
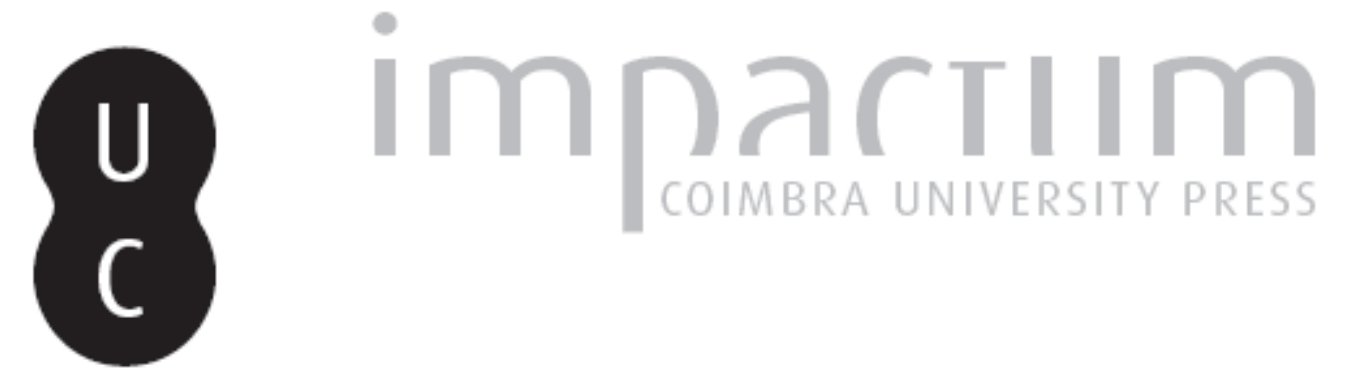

\title{
Uma lápide romana inédita de Porto de Mós
}

\author{
Autor(es): $\quad$ Moreira, José Beleza
}

Publicado por: Imprensa da Universidade de Coimbra

URL persistente:

URI:http://hdl.handle.net/10316.2/45706

DOI:

DOI:https://dx.doi.org/10.14195/1647-8657_21_5

Accessed : $\quad$ 26-Apr-2023 12:59:56

A navegação consulta e descarregamento dos títulos inseridos nas Bibliotecas Digitais UC Digitalis, UC Pombalina e UC Impactum, pressupõem a aceitação plena e sem reservas dos Termos e Condições de Uso destas Bibliotecas Digitais, disponíveis em https://digitalis.uc.pt/pt-pt/termos.

Conforme exposto nos referidos Termos e Condições de Uso, o descarregamento de títulos de acesso restrito requer uma licença válida de autorização devendo o utilizador aceder ao(s) documento(s) a partir de um endereço de IP da instituição detentora da supramencionada licença.

Ao utilizador é apenas permitido o descarregamento para uso pessoal, pelo que o emprego do(s) título(s) descarregado(s) para outro fim, designadamente comercial, carece de autorização do respetivo autor ou editor da obra.

Na medida em que todas as obras da UC Digitalis se encontram protegidas pelo Código do Direito de Autor e Direitos Conexos e demais legislação aplicável, toda a cópia, parcial ou total, deste documento, nos casos em que é legalmente admitida, deverá conter ou fazer-se acompanhar por este aviso.

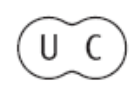


FACULDADE DE LETRAS

INSTITUTO DE ARQUEOLOGIA

\section{CONIMBRIGA}

VOLUMEXXI

UNIVERSIDADE DE COIMBRA

1982 
José Beleza Moreira

Professor do Ensino Secundário

UMA LÁPIDE ROMANA INÉDITA DE PORTO DE MÓS

Conimbriga, XXI, 1982, p. 143-149

SUMÁRIO: Publica-se uma inscrição funerária inédita que hoje se encontra em Ribeira de Baixo (Porto de Mós) e que teria sido encontrada em local próximo. A lápide, que datará dos fins do século i d.C., constitui o primeiro testemunho da gens Aufidia em Portugal.

RÉSU MÉ: Une inscription inédite trouvée à Ribeira de Baixo (Porto de Mós) est attribuée par l'auteur à la fin du 1er siècle ap. J.G. La gens Aufidia était jusqu'ici inconnue au Portugal. 
(Página deixada propositadamente em branco) 


\section{UMA LÁPIDE ROMANA INÉDITA DE PORTO DE MÓS*}

Encontra-se no lugar de Ribeira de Baixo, freguesia de S. João, concelho de Porto de Mós, uma placa romana em mármore com inscrição funerária, metida na parede, por sobre a porta de uma casa em ruínas, pertença dos herdeiros de Manuel Vieira do Rosário, a qual teria provindo de um antigo cemitério ali perto, em Santo Estêvão $\left({ }^{1}\right)$.

Náo nos consta que já tenha sido estudada.

Dimensões: $47 x 62,5 x$ ?

Campo epigráfico: $32,5 \times 47$

$\mathrm{D}$ (is) $\mathrm{M}$ (anibus) S(acrum) / AVFIDIAE / RVSTICAE / $\mathrm{AN}$ (norum) $\boldsymbol{\nabla}$ XVII (septem et decem) * FILIAE $l^{\circ} Q$ (uintus) * LIGVRIVS / RVSTICVS * P(onendum) C(uravit)

Consagrado aos deuses Manes. Quinto Ligúrio Rústico mandou fazer à filha, Aufídia Rústica, de dezassete anos.

Altura das letras: 4 .

Espaços interlineares: 1: 3,5/4; 2 e $3: 0,4 ; 4$ e $5: 0,2 ; 6: 0,4$; 7: 2,3 .

(*) Desejamos expressar os nossos sinceros agradecimentos ao Ex. ${ }^{m o}$ Sr. Dr. José d'Encarnaçâo pela prestimosa ajuda que se dignou prestar-nos, e sem a qual não teria sido possível o presente trabalho. Ao Dr. A. J. Nunes Pinto agradecemos a colaboração prestada na elaboração do mapa 2.

p) Agradecemos à Sr.a D. Denise Vieira do Rosário Morgado esta informação, bem como a autorização que nos concedeu para o estudo da peça. Da zona procede igualmente a lápide referida por D. Domingos de Pinho Brandão («Conimbriga», XI, 1972, p. 127-129). 
O monumento está completo e em bastante bom estado de conservação, apesar da fractura ocorrida no canto inferior direito. Tem moldura de garganta reversa limitando o campo epigráfico, que é rebaixado em relação a ela. Cobria-o espessa camada de cal, que não pudemos limpar por completo - daí que a foto obtida não seja da melhor qualidade. No entanto, a leitura faz-se sem dificuldades.

A paginação foi feita atendendo mais ao sentido do texto que a alinhamentos à esquerda ou à direita ou segundo um eixo de simetria. Assim, toda a inscrição nos aparece puxada para a esquerda, dando porém a impressão que se procurou dispor as linhas três a três, tendo em conta a necessidade de não cortar palavras. Pontuação triangular.

Os caracteres, muito bem gravados, são do tipo monumental quadrado: o $Q$ bem circular, o $\mathrm{G}$ de haste pequena e vertical, a curvatura do $R$ não toca a haste vertical, as barras do $F$ estão muito em cima e são curtas.

$\mathrm{O}$ texto reveste-se do maior interesse pela onomástica que nos revela. Assim, Aufidia Rustica é, que saibamos, a primeira representante, encontrada em território português, da gens Aufidia, que embora de origem plebeia (T.L.L., II, p. 1338 s.v. «Aufidius»), outros membros ilustres registou na Península, nomeadamente em Tarragona (ver mapa 1). O seu cognome, Rusticus, que curiosamente herda do pai em vez do gentilicio (2), é típico da África ( ${ }^{3}$ ) e regista-se sobretudo no sul da Península Ibérica, zona tradicionalmente mais em contacto com a África (ver mapa 2). Naturalmente relacionado com a agricultura, o cognome pode ser indicativo de família de proprietários rurais. De salientar também que se regista no período republicano (135/27) um $M$. Aufidius Rusticus (Kajanto, o. c., p. 310).

${ }^{2}$ ) Será o gentilicio da mãe? Em Tarragona (CIL II $4326=1$ LER $3876=R 1 T$ 383) regista-se um exemplo que pode ser idêntico a este: Sulpicia Aeliana é filha de M. Vettidius Aelianus e de Sulpicia Calagurritana; ou seja, recebeu o gentilicio da mãe e o cognome do pai. Ver outros exemplos de transmissão do gentilicio materno em CIL II, p. 1199.

(3) IIro Kajanto, The Latin Cognomina, Helsínquia, 1965, p. 310, indica que, de 344 exemplos registados no mundo romano, 135 provêm de África. 
O gentilicio Ligarius, que apenas identifica mais três personagens na Península Ibérica, todos dentro dos limites da Lusitânia $\left({ }^{4}\right)$, vem trazer uma importante achega ao muito debatido problema da existência de um estrato ligure na Hispânia (5), uma vez que a sua origem etimológica parece efectivamente assentar no topónimo Liguria (Kajanto, p. 196). Na realidade, toda a antroponimia patente nesta epígrafe aponta para a identificação de personagens não-autóctones, oriundos da Península Itálica, provavelmente com passagem pela costa africana.

A presença de invocação aos deuses Manes, o uso do dativo, a simplicidade com que são indicados os laços familiares e a paleografia, permitem datar a inscrição dos fins do séc. i da nossa era.

\section{AUFIDIUS}

1. Tarragona - CIL II 4122 (=ILER 1311); CIL II 4137 ( =ILER 5816); CIL II 4145 ( =ILER 5621); CIL 4146 (=ILER 3889); CIL II 4196 (=ILER 1549); CIL II 4197 (=ILER 1605); CIL II $4320 \quad(=I L E R \quad 5500)$; $C I L \quad$ II $4336 \quad(=I L E R \quad 5169) ; \quad C I L \quad$ II $4448 \quad(=I L E R$ 4812).

2. Cós (Leiria) - CIL II 344.

3. Cerra de Pozza (cerca de Brozas) - CIL II 742 ( $=I L E R$ 668).

4. Poza de la Sai (cerca de Brozas) - CIL II 746 ( $=I L E R$ 929).

5. Caparra - CIL II 815.

6. Jerica - CIL II 3993 (=ILER 1274).

$\left(^{4}\right)$ Mérida (ILER 3669), Idanha-a-Velha (ILER 4854), e Talavera de la Reina (CIL II 923 - ILER 3862).

(5) Sobre esta questão ver: J. Leite de Vasconcelos, Religiões da Lusitânia, vol. II, Lisboa, 1905, p. 54 e 273/4; Ramon Menendez Pidal, Ligures o Ambroilirios en Portugal «Revista da Faculdade de Letras de Lisboa», 2. a série, 10 (1-2), 1944, p. 5-17 ; Maria de Lourdes Albertos Firmat, Nuevos Antroponimos Hispanicos, «Emerita», XL, 1972, p. 296, s. v. «Ligustini», com mais bibliografìa. 
7. Barcelona - CILII 4561 (=ILER 3708); ILER 1683 (=5631).

8. Villafranca de los Barros (Badajoz) - CIL II 5354 (=ILER 2050).

9. Salvatierra de los Barros - CIL II 1014 ( =ILER 4885).

10. Denia _CILII 3589 ( =IL4740).

11. Palma de Mallorca - CIL II 5988 ( 4311).

12. Mosteiro de S. Paulo (Córdoba) - CIL II 2301 ( 6104).

13. Madrid-CIL II 4969-10 (ILER 5908).

14. Ribeira de Baixo (Porto de Mós).

\section{RUSTICUS}

1. Tarragona - C/L II 4126 (=ILER 1312); C IL II 4137 ( = ILER 5816); C 1 L II 4970445; 6026; 156; CIL II $4430=$ RIT 470.

2. Penalva (Viseu) - CIL II 421 ( =ILER 5043).

3. Mérida-CIL II 548 ( =IL2673).

4. Barcelona - CILII $4579($ 4725).

5. Cartama-CIL II 1952 ( 414); CIL II 1953 (=ILER 1071); CIL II 1959 (=ILER 6467) (Rutici = = Rustici?); CIL II 1961 (=ILER 4080); II 1962 ( $\quad$ 1LER5218).

6. El Castillon-Antequera (Málaga) - CIL II 2015 ( = ILER 1487).

7. Cádiz-CILII 1882 (=ILER 2936); ILER 2792.

8. Granada-CILII 5501 (2833).

9. Sagunto - CILII 6028 ( 4612).

10. Valença -CILII 3751 (=ILER 4205); CIL II 6245-1 (=ILER 5927).

11. Oliva de Alicante (Valença) - II 5974 ( 3633).

12. Villalonga (Valencia) $-C I L I I$ $6009(=I L E R$ 2146)

13. Jimena de la Frontera - CIL II 1330 (=ILER 1501); CIL II 1332 ( =ILER 5845); CIL II 1333 (=ILER 6536). 
14. Entre Trujillo e Cáceres $-C I L$ II 689 (Ustici = Rustici ?).

15. Valdefuente (Cáceres) - ILER 2681.

16. Andujar (Jaén) - CIL II $2121\{$-ILER 2080 =6076).

17. Lora del Rio (Sevilha) - CIL II 1056 (=ILER 1458).

18. Alcolea del Rio (Sevilha) - CIL II 1064 ( =ILER 1459); CIL II 1070 (=ILER 4219).

19. Utrera (Sevilha) - CIL II 1282 (=ILER 1122); CIL II 1283 ( =ILER 1293).

20. El Coronil (Sevilha) - CIL II 1371 \{ - ILER 1107).

21. Villafranca de los Palacios (Sevilha) - ILER 6798.

22. Sevilha - CIL II 1175 (=ILER 2191).

23. Villalba de Alcor (Sevilha) - CIL II 1267 ( =ILER 362).

24. Peñaflor (Sevilha) - CIL II 2326 (=ILER 418).

25. Cordoba - CIL II 1653 (=ILER 5343); CIL II 2220 (=ILER 1548); CIL II $2242\{=I L E R$ 3442).

26. Ecija - CIL II 1510 (=ILER 3567).

27. Itálica - CIL II 1158 (=ILER 3192)

28. Cazaba de la Sierra (Toledo) - CIL II 1048 (=ILER 5371).

29. Languardia (Arula) - ILER 6775.

30. Priego (Bética) - CIL II $1656\{=I L E R$ 3600).

31. Castro del Rio (Bética) - CIL II 1570 (=ILER 1079).

32. Sabora (Attubi-Bética) - CIL II 1431 (=ILER 3970).

33. Hispalis (Sevilha) - CIL II $4962^{2}$.

34. Málaga - CIL II 1967 (=ILER 503).

35. Elvas-《Conimbriga», XVI, 1977, p. 53.

36. S. Sebastião do Freixo (Leiria) - CIL II 348 (=ILER 4206).

37. Ribeira Plana (Leiria) - CIL II 361.

38. Ribeira de Baixo (Porto de Mós). 


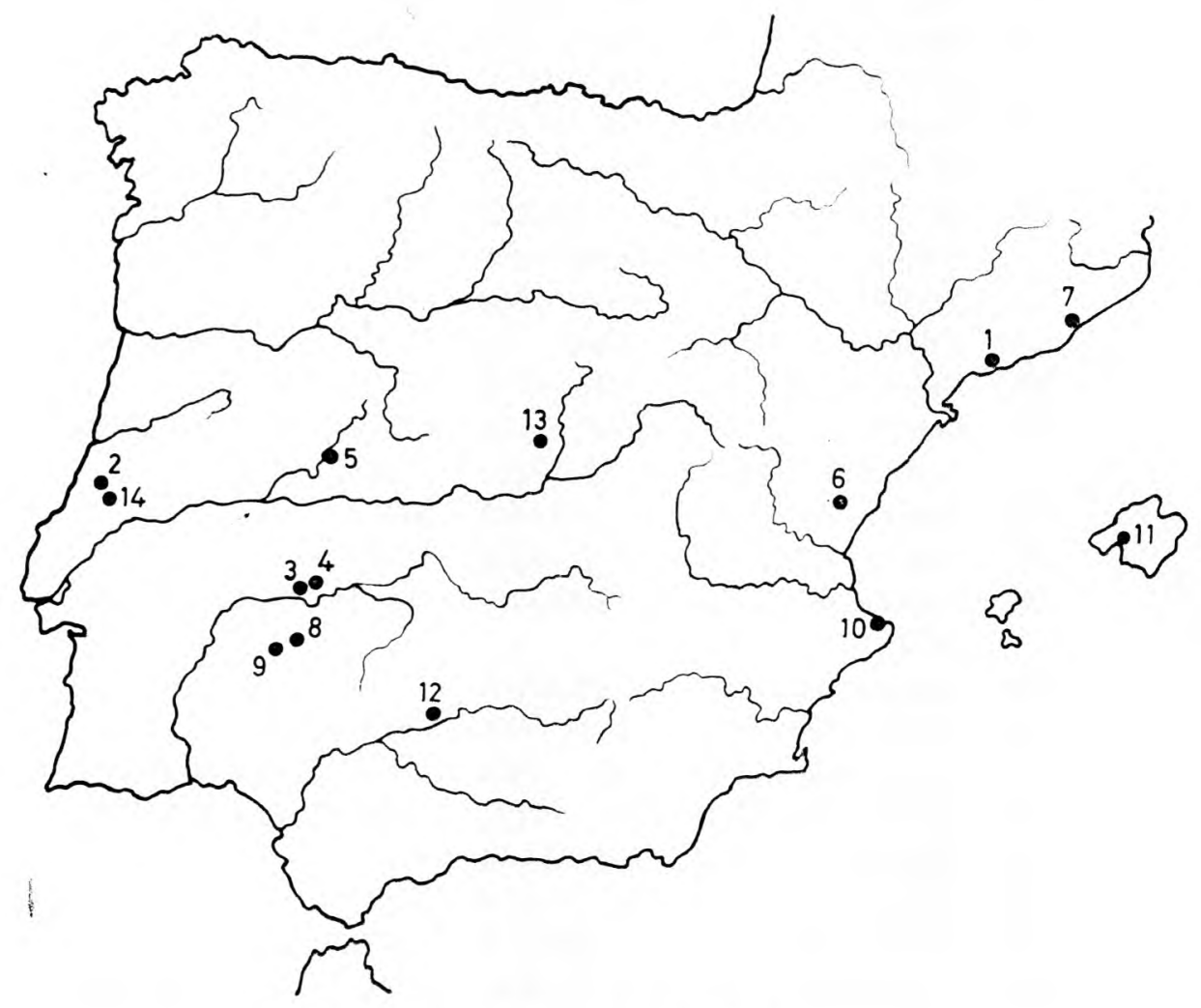

Mapa 1 - AUFIDIUS 


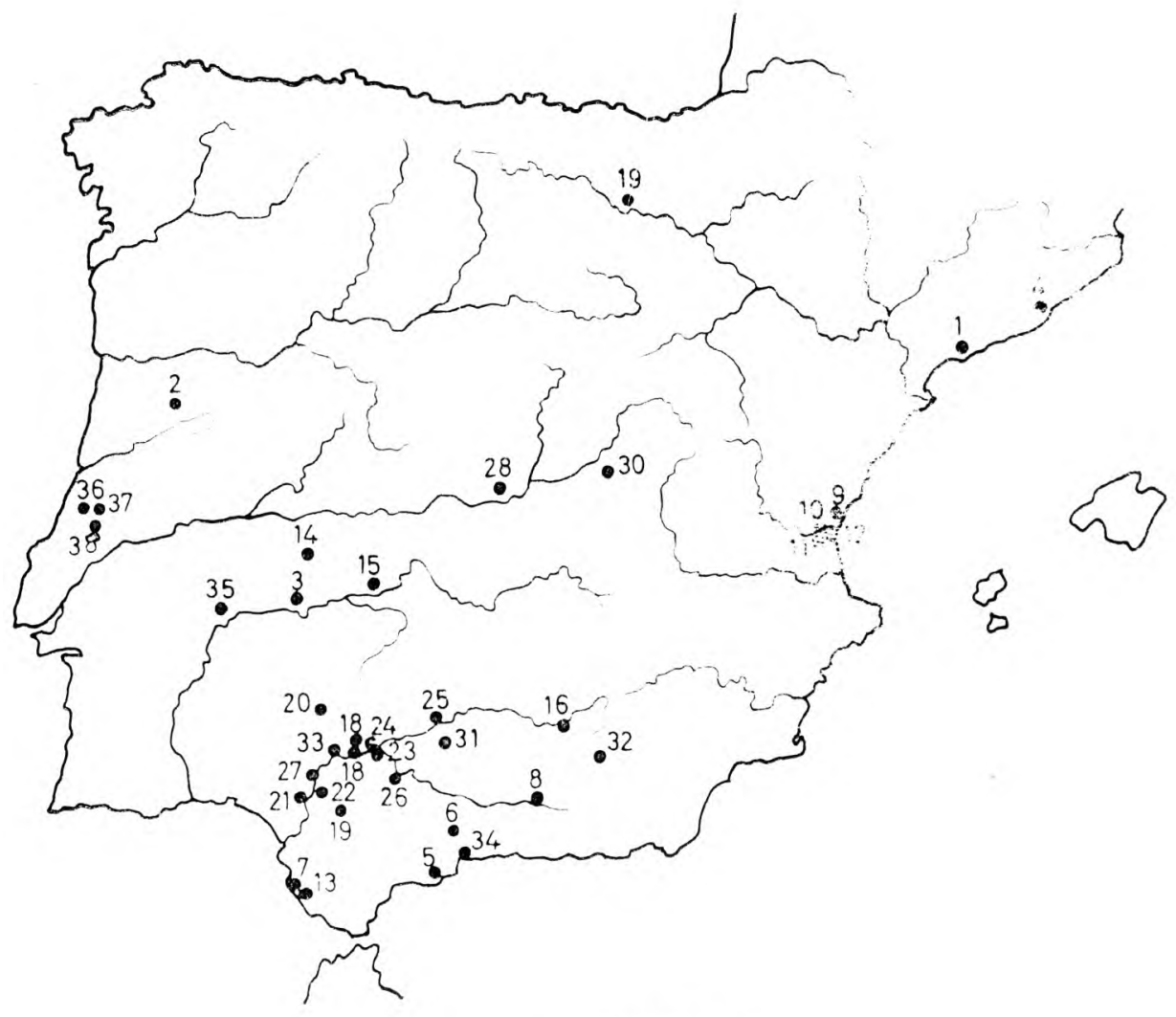

Mapa 2 - RUSTICUS 
(Página deixada propositadamente em branco) 


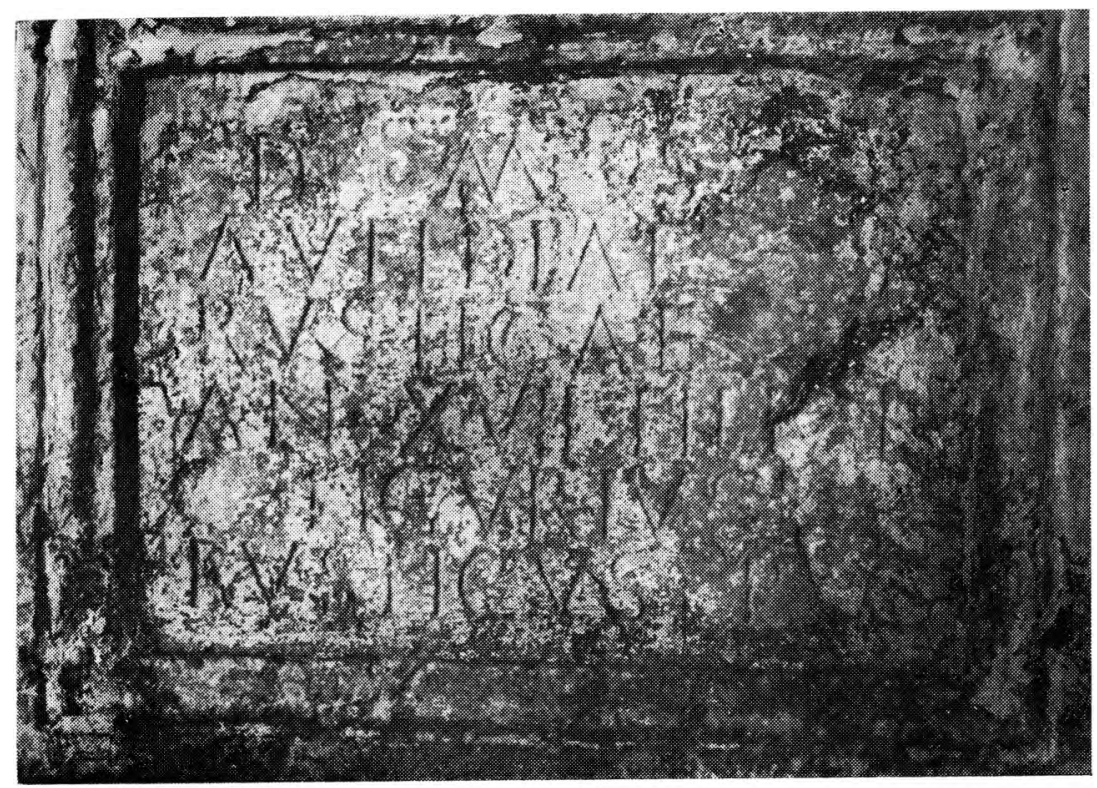




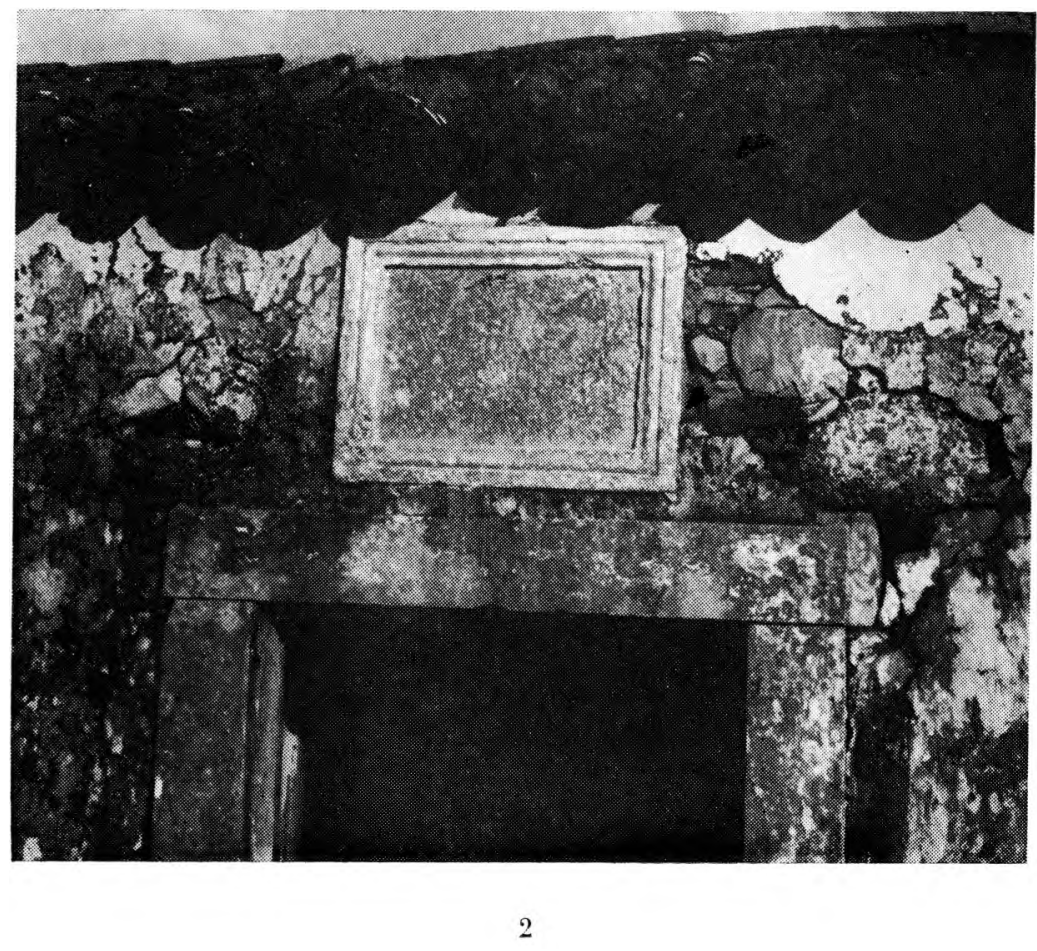

